\title{
Knowledge and use of asthma control measurement tools in the management of asthma: a survey of doctors working in family and internal medicine practice in Nigeria.
}

\author{
Olufemi Olumuyiwa Desalu ${ }^{1}$, Cajetan C. Onyedum², Adekunle O. Adeoti ${ }^{3}$, \\ Obianuju B. Ozoh ${ }^{4}$, Joseph O Fadare ${ }^{5}$
}

1. Department of Medicine, University of Ilorin Teaching Hospital

2. Department of Medicine, University of Nigeria Teaching Hospital Ituku Ozalla Enugu

3. Department of Medicine, Ekiti State University Teaching Hospital Ado-Ekiti

4. Department of Medicine, Lagos University Teaching Hospital Idi-Araba

5. Department of Pharmacology, Ekiti State University Teaching Hospital Ado-Ekiti

\begin{abstract}
Objective: To investigate the knowledge and use of asthma control measurement (ACM) tools in the management of asthma among doctors working in family and internal medicine practice in Nigeria.

Method: A questionnaire based on the global initiative on asthma (GINA) guideline was self-administered by 194 doctors. It contains 12 test items on knowledge of ACM tools and its application. The knowledge score was obtained by adding the correct answers and classified as good if the score $\geq 9$, satisfactory if score was 6-8 and poor if $<6$.

Results: The overall doctors knowledge score of ACM tools was 4.49 \pm 2.14 (maximum of 12). Pulmonologists recorded the highest knowledge score of $10.75 \pm 1.85$. The majority (69.6\%) had poor knowledge score of ACM tools. Fifty (25.8\%) assessed their patients' level of asthma control and 34(17.5\%) at every visit. Thirty-nine (20.1\%) used ACM tools in their consultation, 29 $(15.0 \%)$ of them used GINA defined control while $10(5.2 \%)$ used asthma control test (ACT). The use of the tools was associated with pulmonologists, having attended CME within six months and graduated within five years prior to the survey.

Conclusion: The results highlight the poor knowledge and use of ACM tools and the need to address the knowledge gap.

Keywords: asthma control, knowledge, use, control tools, Nigeria

DOI: http://dx.doi.org/10.4314/ahs.v16i2.16

Cite as: Desalu OO, Onyedum CC, Adeoti AO, Ozob OB, Fadare JO. Knowledge and use of asthma control measurement tools in the management of asthma: A survey of doctors working in family and internal medicine practice in Nigeria. Afri Health Sci 2016;16(2): 480-489. http://dx.doi.org/10.4314/abs.v16i2.16
\end{abstract}

\section{Introduction}

Asthma is a non-communicable disease that affects about 235 million people worldwide ${ }^{1}$. The global initiative on asthma (GINA) estimates the prevalence of clinical asth$\mathrm{ma}$ in Nigeria to be $5.4 \% \%^{2}$. From the two international study of asthma and allergies in childhood conducted 7 years apart in 1995 and in 2001-2002. The prevalence of current wheeze which is used in defining asthma increased
Corresponding author:
Olufemi Olumuyiwa Desalu,
Department of Medicine,
University of Ilorin Teaching Hospital
PMB 1459, Ilorin
Tel: +2348035025771 .
Email:femuy1967@yahoo.co.uk

from $10.7 \%-13.0 \%$ with a mean change just above $0.3 \%$ in prevalence per year ${ }^{1}$. These two standardized studies indicate an increase in the prevalence of asthma in Nigeria while the infrastructures for managing this condition to internationally endorsed standards of care are not widely available ${ }^{3}$.

The goal of asthma therapy according to GINA is to achieve and maintain disease control ${ }^{4}$. GINA guideline which is widely used in Nigeria is a global strategy for asthma management and prevention developed by the World Health Organization in collaboration with $\mathrm{Na}-$ tional heart, lung, and blood institute ${ }^{2}$. There is no national asthma treatment guideline in the country, so GINA is easily adapted to our local setting ${ }^{3}$. According to the GINA guidelines before 2006 a stepwise approach to treatment based on the assessment of asthma 
severity was recommended ${ }^{2}$. However this approach of using severity as an outcome measure has challenges in the management of the condition because of its limited value in predicting what treatment is required and what the response to that treatment would be. The benefits of managing asthma on the basis of its control are that it seems easier to use than severity, as asthma is a variable disease and it better reflects the effects of the disease and medication needs ${ }^{2,4}$. The subsequent GINA guidelines after 2006 recommended a control-based management, marking a departure from severity-based management ${ }^{2,4,5}$.

Asthma control may be assessed by individual subjective and objective measures. The subjective measures include daytime symptoms, nocturnal awakening, limitation of activity, b2-agonist use as rescue medications and emergency visit and hospitalisation, while the objective measures include lung function tests using peak flow meters or spirometer, sputum eosinophils, exhaled nitric oxide FENO and nonspecific bronchial reactivity ${ }^{2,4,6,7}$. It is believed that objective measures are more reliable than subjective ones, however most of them may not be feasible to use or recommend in clinical practice due to some factors. It has been documented that there is a poor correlation between lung function test and the level of symptoms perceived by patients ${ }^{8}$. In addition, the use of exhaled nitric oxide FENO in asthma treatment has not resulted in improving disease control or enabled a reduction in dose of inhaled corticosteroids ${ }^{2,4}$.

In some countries there are resource and technical constraints, and infrastructures for performing spirometry, sputum eosinophils, exhaled nitric oxide FENO and nonspecific bronchial reactivity test are expensive or not widely available ${ }^{3,7}$. The requirements of an ideal tool to measure asthma control are easy application and administration at all levels of healthcare, less time consuming, reproducible, easy scoring system, responsive to changes in asthma control over time, provide guidance to titrate treatment and perform equally well with or without lung function data ${ }^{7}$. Most objective measures lack the requirements of an ideal tool therefore, the use of questionnaires to record patient-reported outcomes is perhaps the best tools to assess asthma control ${ }^{7}$. The tools recommended are GINA working scheme, Asthma Control Scoring System (ACSS), Asthma Control Questionnaire (ACQ), Asthma Therapy Assessment Questionnaire (ATAQ) and Asthma
Control Test $(\mathrm{ACT})^{4,5}$. The use of shortened 5 -item version ACQ (ACQ-5) requires no information on both lung function test and $\beta 2$-agonist use as rescue medications while the uses of ATAQ and ACT require no lung function test $t^{3,4,7,9}$. ATAQ and ACT measures control over the previous four weeks and therefore is more vulnerable to the problem of recall ${ }^{7}$. The ACT is easy to administer, easy to understand and can be easily applied in the clinic, its scoring system is simple and allows categorisation into controlled and uncontrolled states ${ }^{7}$.

The Gaining Optimal Asthma Control (GOAL) study has shown that current asthma treatment can achieve good control in patients, however in real life asthma control is still not often achieved ${ }^{10-16}$. Poor asthma control is due to several factors which are related to the patients, physicians' behaviour and adherence to the treatment guidelines $^{14-22}$. Studies have been conducted on knowledge of asthma and its management amongst medical doctors in Nigeria ${ }^{23}$ however, the knowledge and use of asthma control management tools among doctors has not been adequately investigated. We therefore designed this study to investigate the knowledge and use of asthma control measurement tools in the management of asthma among doctors working in family and internal medicine practice in Nigeria.

\section{Methods \\ Study design}

This was a descriptive cross-sectional study among doctors in the family and internal medicine practice the selected public and private hospitals in Nigeria. The survey was carried out from June 2012 to December 2012.

\section{Study setting}

The study setting were public and private hospitals located in five of the six geopolitical zones in Nigeria, these two categories of hospitals were selected because majority of the population patronizes them for orthodox medical care. Participating hospitals were chosen for reasons of convenience and easy coordination by the investigators. The selected study sites were four University teaching hospitals, three Federal medical centers (FMC) and private hospitals respectively. The University teaching hospitals and Federal medical centers (FMC) are accredited for postgraduate medical training of medical doctors, and they cater for the primary, secondary and 
tertiary care of the population in their respective regions. The three private hospitals are located in urban areas and cater mostly for upper and middle class and provide primary and secondary healthcare services. The delivery of asthma care in Nigeria is usually through the conventional general and medical outpatient clinic, respiratory clinic and emergency room.

\section{Study population}

The study population consisted of resident doctors (junior and senior registrars) and specialist consultants from the departments of internal and family medicine and medical officers working as general duty doctors in all the selected hospital. The participating doctors all have access to and treated asthma patients. For the sake of clarity, the medical officers are post-internship doctors with full medical license registration but are yet to commence residency training.

\section{Sample size}

Four hundred and ninety-five doctors were working in the selected hospitals and 250 of them regularly have access to and treated asthma patients and were eligible to participate in the study.

\section{Sample selection}

Convenience sampling which is a non-probability method of sampling was employed in selecting participants for the study. Only the eligible doctors working in the participating hospitals were recruited to remove selection bias. The eligible doctors were informed about the study and then given a questionnaire; the purpose of the study was explained to them in the information note attached to the questionnaire. Those who participated in the pretesting of the survey instrument, as well as those who declined to participate in the study or failed to append their signature (written consent) or return the questionnaire, were excluded from the study.

\section{Survey instrument}

A pre-tested, self-administered and semi-structured questionnaire was prepared based on some contents of the GINA guidelines. The contents of GINA guideline on asthma control tools and application of ACM tools in long-term care of asthma were incorporated into the questionnaire. There were 12 items on knowledge of asthma control tools, three questions on the use of asthma control measurement tools in the preceding 12 months and one on continuing medical education on asthma. The 12 test items on the knowledge of asthma control tools measured doctors' familiarity $=8$ and application of ACM tools in clinical practice $=4$. After the development of the questionnaire, the contents were reviewed by four pulmonologists and there was $90 \%$ agreement on the 16 main test items and their wordings. The questionnaire was thereafter tested in a pilot study involving 10 internal medicine residents to ascertain that the questions were acceptable and their wordings well understood. In addition, the survey instrument was designed to collect respondents' socio-demographic information, the location of practice, years of experience (A copy of the questionnaire is attached as additional file).

\section{Measurement of knowledge of ACM tools}

The knowledge assessment covers the contents of ACM tools and its application and application in stepwise management ${ }^{24}$.

\section{Data handling and analysis}

All correct answers in the questionnaire were assigned a weight of plus one $(+1)$ and all wrong answers or answers left blank were scored zero. The knowledge score was determined by adding the scores obtained for each test item. The maximum knowledge score possible was 12 . The Knowledge scores were classified as good if score $\geq$ 9, satisfactory if score was 6-8 and Poor if the score was $<6$. Data analysis was done using the Statistical Package for the Social Sciences, Version 16.0 (SPSS Inc., Chicago, IL, USA). Descriptive statistics were used to report the general characteristics of the respondents. All data are presented as mean (standard deviation SD) and percentages where appropriate. Analysis of variance (ANOVA) was used to compare the doctors' mean scores of asthma control knowledge by age, gender, year since of graduation, rank in the hospital and specialty. Spearman's correlation was used to determine factors associated with the use of asthma control measurement tool. A p-value < 0.05 was considered significant.

\section{Ethical approval}

This study was approved by the ethical review committees of the participating public hospitals. Approval was also given by the head of the private hospitals. Each completed questionnaire was assigned a numerical code and any form of identification was excluded to ensure anonymity 


\section{Results}

\section{General characteristics of the Doctors}

A total of 250 doctors received a copy of the questionnaire; $194(77.6 \%)$ returned and completed questionnaires (78\% response rate). Out of 194 doctors recruited into the study, $149(76.8 \%)$ were males, $114(55.7 \%)$ were working in the Department of Internal Medicine and $129(66.5 \%)$ working in the University teaching hospital. The mean age of the participating doctors was $34.2 \pm 4.2$ years and the median duration of the year since graduation was 7 years (range 1-22). One hundred and seventytwo $(88.7 \%)$ doctors attended a CME program on asthma management prior to the study, $46(23.7 \%)$ attended in less than 6 months, 22(11.3\%) within 6- 12 months and $36(18.6 \%)$ within 1-2 years (Table 1). Out of the 172 CME attendees, (126:70.7\%) reported that emphasis was on the GINA strategy of assessment of asthma control and management.

Table 1: General characteristics of the Doctors

\begin{tabular}{|c|c|c|}
\hline Characteristics & $\mathbf{n}$ & $\%$ \\
\hline $\begin{array}{l}\operatorname{Age}(\text { yrs }) \\
<35 \\
>35\end{array}$ & $\begin{array}{c}129 \\
65\end{array}$ & $\begin{array}{l}66.5 \\
33.5\end{array}$ \\
\hline $\begin{array}{l}\text { Mean Years after graduation(yrs) } \\
<5 \\
6-9 \\
>10\end{array}$ & $\begin{array}{c}50 \\
103 \\
41\end{array}$ & $\begin{array}{l}25.8 \\
53.1 \\
21.1\end{array}$ \\
\hline $\begin{array}{l}\text { Sex } \\
\text { Male } \\
\text { Female }\end{array}$ & $\begin{array}{c}149 \\
45\end{array}$ & $\begin{array}{l}76.8 \\
23.2\end{array}$ \\
\hline $\begin{array}{l}\text { Types of hospital } \\
\text { University Teaching Hospital/FMC } \\
\text { General /Private Hospital }\end{array}$ & $\begin{array}{c}186 \\
8\end{array}$ & $\begin{array}{l}95.6 \\
4.1\end{array}$ \\
\hline $\begin{array}{l}\text { Specialty of practice } \\
\text { Internal Medicine } \\
\text { Family Medicine } \\
\text { Pulmonary Medicine }\end{array}$ & $\begin{array}{l}108 \\
80 \\
6\end{array}$ & $\begin{array}{l}55.7 \\
41.2 \\
3.1\end{array}$ \\
\hline $\begin{array}{l}\text { Rank /level of training } \\
\text { Medical officer } \\
\text { Junior Registrar } \\
\text { Senior registrar } \\
\text { Consultants } \\
\text { Pulmonologist }\end{array}$ & $\begin{array}{c}61 \\
80 \\
40 \\
9 \\
4\end{array}$ & $\begin{array}{l}31.4 \\
41.2 \\
20.1 \\
4.6 \\
2.6\end{array}$ \\
\hline $\begin{array}{l}\text { CME attendance } \\
<6 \text { month } \\
6-12 \text { month } \\
1-2 \text { years } \\
>2 \text { years } \\
\text { None }\end{array}$ & $\begin{array}{l}46 \\
22 \\
36 \\
66 \\
24\end{array}$ & $\begin{array}{l}23.7 \\
11.3 \\
18.6 \\
34.0 \\
12.4\end{array}$ \\
\hline
\end{tabular}

CME-continuing medical education

FMC -Federal medical centre 
Knowledge of the content of ACM tools - The doctors' scores on the knowledge of the content of ACM tools was 2.91土.1.57 out of a maximum possible score of 8.Pulmonologist significantly recorded the highest score of $7.00 \pm 1.41$ while the medical officers recorded the lowest score of $2.43 \pm 1.44$. Doctors who worked in university hospital recorded a higher score when compared with

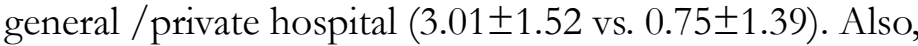
doctors who attended a CME on asthma in less than six month had a better score when compared with doctors who attended CME after six months.

Knowledge of application ACM tools in stepwise management

The doctors' scores on the knowledge of the application ACM tools in stepwise management $1.58 \pm 1.08$ out of a maximum possible score of 4 . Pulmonologist signifi- cantly recorded the highest score of $3.75 \pm 0.50$ while the senior registrar recorded the lowest score of 1.35 \pm 1.12 . The doctors who were males worked in general / private hospital and had attended a CME on asthma in less than six month had a better score when compared with other categories of doctors.

\section{Knowledge of asthma control measurement (ACM) tools}

The doctors' overall scores on the knowledge of ACM tools was $4.49 \pm 2.14$ out of maximum possible score of 12. Pulmonologist recorded the highest score of $10.75 \pm 1.85$ while the medical officers recorded the lowest score of $4.23 \pm 1.83$. The knowledge of ACM tools was significantly higher among doctors in pulmonary special-

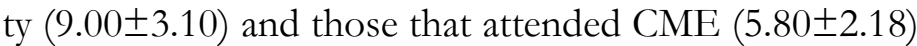
in less than six months (Table 2).

Table 2: Knowledge Score of Asthma Control Tool by Doctors Characteristics

\begin{tabular}{|c|c|c|c|c|}
\hline Variables & $\mathbf{n}$ & $\begin{array}{l}\text { Knowledge } \\
\text { of the content } \\
\text { ACM tools }\end{array}$ & $\begin{array}{l}\text { Knowledge } \\
\text { of Application of } \\
\text { ACM tools in } \\
\text { management }\end{array}$ & $\begin{array}{l}\text { Total } \\
\text { knowledge } \\
\text { Score of ACM } \\
\text { tools } \\
\end{array}$ \\
\hline No of question per section & & 8 & 4 & 12 \\
\hline $\begin{array}{l}\text { Mean score per section } \\
\text { Age(yrs.) }\end{array}$ & & $2.91 \pm .1 .57$ & $1.58 \pm 1.08$ & $4.49 \pm 2.14$ \\
\hline$<35$ & 129 & $3.00 \pm 1.48$ & $1.57 \pm 1.01$ & $4.57 \pm 1.95$ \\
\hline$>35$ & 65 & $2.74 \pm 1.73$ & $1.59 \pm 1.10$ & $4.32 \pm 2.48$ \\
\hline $\begin{array}{l}\text { Mean Years } \\
\text { graduation(yrs.) }\end{array}$ & & & & \\
\hline$<5$ & 50 & $2.88 \pm 1.12$ & $1.64 \pm 1.14$ & $4.52 \pm 1.62$ \\
\hline $6-9$ & 103 & $2.92 \pm 1.64$ & $1.50 \pm 1.05$ & $4.41 \pm 2.13$ \\
\hline$>10$ & 41 & $2.95 \pm 1.88$ & $1.71 \pm 1.10$ & $4.66 \pm 2.69$ \\
\hline Sex & & & & \\
\hline Male & 149 & $2.97 \pm 1.53$ & $1.68 \pm 1.05$ & $4.65 \pm 2.12$ \\
\hline Female & 45 & $2.71 \pm 1.70$ & $1.24 \pm 1.11 *$ & $3.96 \pm 2.12$ \\
\hline Types of hospital & & & & \\
\hline University Teaching Hospital/FMC & 186 & $3.01 \pm 1.52$ & $1.54 \pm 1.06$ & $4.54 \pm 2.16$ \\
\hline General/Private Hospital & 8 & $0.75 \pm 1.39 *$ & $2.50 \pm 1.20 *$ & $3.25 . \pm 0.89$ \\
\hline Specialty of practice & & & & \\
\hline Internal Medicine & 108 & $3.02 \pm 1.34$ & $1.37 \pm 1.05$ & $4.39 \pm 1.96$ \\
\hline Family Medicine & 80 & $2.52 \pm 1.57$ & $1.79 \pm 1.01$ & $4.29 \pm 1.93$ \\
\hline Pulmonary Medicine & 6 & $6.17 \pm 1.72 *$ & $2.83 \pm 1.47 *$ & $9.00 \pm 3.10^{*}$ \\
\hline Rank /level of training & & & & \\
\hline Medical officer & 61 & $2.43 \pm 1.44$ & $1.83 \pm 1.00$ & $4.23 \pm 1.83$ \\
\hline Junior Registrar & 80 & $3.03 \pm 1.36$ & $1.40 \pm 1.03$ & $4.43 \pm 1.85$ \\
\hline Senior registrar & 40 & $3.03 \pm 1.64$ & $1.35 \pm 1.12$ & $4.38 \pm 2.38$ \\
\hline Consultants & 9 & $2.89 \pm 1.27$ & $1.67 \pm 0.87$ & $4.56 \pm 1.24$ \\
\hline Pulmonologist & 4 & $7.00 \pm 1.41 *$ & $3.75 \pm 0.50 *$ & $10.75 \pm 1.85^{*}$ \\
\hline CME attendance & & & & \\
\hline$<6$ month & 46 & $3.85 \pm 1.59$ & $1.96 \pm 1.16$ & $5.80 \pm 2.18$ \\
\hline 6-12 month & 22 & $2.64 \pm 1.53$ & $1.00 \pm 0.87$ & $3.64 \pm 1.71$ \\
\hline $1-2$ years & 36 & $2.89 \pm 1.79$ & $1.94 \pm 0.98$ & $4.83 \pm 2.20$ \\
\hline$>2$ years & 66 & $2.52 \pm 1.34$ & $1.30 \pm 0.94$ & $3.82 \pm 1.78$ \\
\hline None & 24 & $1.58 \pm 1.14^{*}$ & $1.58 \pm 1.21 *$ & $4.08 \pm 2.06^{*}$ \\
\hline
\end{tabular}

Total number of physicians $=194$. Results expressed in mean and $\%$ mean score \pm Standard deviations. $* P<0.05$, SD- Standard deviation, CME-Continuing Medical Education, FMC -Federal Medical Centre 
Out of 194 doctors, 135(69.6\%) recorded poor knowledge score of ACM tools (Table 3). One hundred and forty-four $(74.2 \%)$ of the doctors were unaware of the level of asthma control as the basis for treatment.

\section{Table 3: Grading knowledge of asthma control measurement tool}

\begin{tabular}{lcc}
\hline Grading of knowledge & $\mathbf{n}$ & $\mathbf{\%}$ \\
\hline Good & 7 & 3.6 \\
Satisfactory & 52 & 26.8 \\
Poor & 135 & 69.6 \\
\hline
\end{tabular}

Score $\geq 9$, satisfactory if score was $6-8$ and poor if score was $<6$

Use of asthma control tools

Thirty- nine (20.1\%) of the doctors used ACM tools and $11(5.7 \%)$ used other non-composite measures of asthma control in asthma consultation the previous 12 months. GINA defined control was used by $29(15.0 \%)$ of the doctors, asthma control test (ACT) was used by $10(5.2$
$\%$, while asthma therapy assessment questionnaire (ATAQ) and asthma control questionnaire (ACQ) were not used by any of the doctors (Table 4). Fifty (25.8\%) of the doctors reported that they assessed their patients level of asthma control in past 12 months, and 34(17.5\%) of them assessed control at every visit.

\section{Table 4: Specific tool used in assessing control}

\begin{tabular}{lc} 
Types of tools & $\mathbf{n}(\mathbf{\%})$ \\
\hline GINA & $29(15.0)$ \\
ACT & $10(5.2)$ \\
ACQ & $0(0.0)$ \\
ATAQ & $0(0.0)$ \\
Non-composite measure & $11(5.7)$ \\
None & $144(74.2)$ \\
\hline
\end{tabular}

ACT-Asthma control tool, ATAQ-asthma therapy assessment Questionnaire, ACQ- asthma control questionnaire

Determinants of the use of asthma control measurement tools

The use of control tools was strongly associated with doctors who were working as pulmonologists $(r-+0.19$ $\mathrm{p}=0.008\}$, graduated $<5$ year $(\mathrm{r}-0.19 \mathrm{p}=0.020)$ and attended CME in less than six months $(\mathrm{r}-+0.39 \mathrm{p}=<$ 0.001). Age and sex were not significantly associated with the use of ACM tools (Table 5). 


\section{Table 5: Determinants of the use of asthma control measurement tools}

\begin{tabular}{llll}
\hline Associated Factors & Crude r & Adjusted r & P values \\
\hline Age of physician & -0.18 & -0.09 & 0.288 \\
<5years after graduation & -0.12 & -0.19 & 0.020 \\
Male & +0.12 & +0.14 & 0.083 \\
University Teaching Hospital & -0.17 & -0.13 & 0.077 \\
Consultant pulmonologist & +0.16 & +0.19 & 0.008 \\
CME in $<$ 6 months & +0.28 & +0.39 & $<0.001$ \\
\hline
\end{tabular}

\section{Discussion}

The main findings of this study show that the overall knowledge of ACM tools was poor. Knowledge score of ACM tools was highest among pulmonologists, doctors in pulmonary specialty and those that attended CME in less than six months when compared to other categories of doctors. Only $20 \%$ of the doctors use ACM tools and $17.5 \%$ assessed their patients' level of control at every visit. The use of control tools was associated with pulmonologists, attendance of CME in less six months and year of graduation $<5$ years.

The poor performance on knowledge of ACM tools is similar to what was reported among GPs and specialists in Italy, however in that study; there was no significant difference in the knowledge of ACM by specialty of practice ${ }^{22}$. In contrast to the Italian study, this study found a significant difference in the knowledge by specialty of practice, as doctors working in pulmonary subspecialty had the highest knowledge score of ACM while doctors working in family practice and medical officers had the lowest score. In a recent study of knowledge of the asthma guidelines among doctors in a tertiary hospital in Southern Nigeria, respiratory physicians' recorded significantly higher scores than other specialist in questions related to disease control ${ }^{25}$. It may not be surprising that the pulmonologists had more knowledge than the rest of the other doctors. This observation is due to their level of training and expertise on the topic, the volume of information and guideline accessibility ${ }^{25}$.

In clinical practice in the last one year, about $20.1 \%$ of the doctors in this study reported the use of ACM tools while $5.7 \%$ used other non-composite measure of asthma control. This trend is not peculiar to Nigeria doctors, as it was reported that doctors in primary care in New
Zealand don't routinely use asthma control measurement tools ${ }^{26}$. This abysmal usage of asthma control tool by the majority of doctors in this study may be as a result of the poor level of awareness of the content of the guideline. When asked about the basis for treatment decision, the majority $(74.2 \%)$ of the doctors were unaware of asthma control as the basis for treatment decisions. The findings may provide some explanation for the poor level of asthma control seen in clinical practice ${ }^{14-16}$, partly due to physician lack of familiarity with the current treatmentguideline ${ }^{24}$.

The use of ACM tool was very low in this study, 15\% used GINA working scheme while $5.2 \%$ used of ACT, and none of the doctors reported the use of ATAQ and ACQ. It was reported that the Asthma Control Test (ACT) is not routinely used in New Zealand primary care $^{26}$. Inadequate use of paper-based instruments by the physician might be multi-factorial, these may include practicality and acceptability of the instruments, inadequate consultation time, lack of reminder systems and the unavailability of asthma control instrument in the clinic. Other factors are poor knowledge of the instrument, ease of interpretation especially in setting where there is no computer application to support interpretation in a busy clinic setting. ${ }^{27-28}$.

In this study, only one in five doctors assessed their patients' level of asthma control at every visit. There is a paucity of data in the literature to compare with this result. This finding is likely due to doctors' lack of understanding of the variable nature of the condition and familiarity of GINA guideline ${ }^{25}$.

The use of control tools was strongly associated with pulmonologists, doctors who graduated $<5$ years and attended CME in less than six months prior to the study. 
This result is in keeping with a previous study which reported that asthma control tool was used by $20 \%$ of GPs compared to $43 \%$ in pulmonologists ${ }^{22}$. The use of ACM tools was also associated with doctors who graduated $<$ 5 years prior to the survey. Doctors who graduated less than five years may not suffer from inertia of practice p $^{27-29}$.

We also observed a significant association between the use of asthma control tool and attendance of CME within 6 months prior to the survey. It is not surprising as $70.7 \%$ of CME attendees reported that there was adequate emphasis on the assessment of asthma control and management. Some studies have shown that a well-tailored CME intervention results in changes in physician behavior, professional practice or health care outcomes ${ }^{30-31}$. Organizing a lot of CME programs and encouraging physicians to participate in these programs might help in improving the knowledge and attitude of physicians towards the use of asthma control measurement tools.

The strength of the present study is the recruitment of participating physicians from five of the six regions of the country and those working in both public and private hospitals which are close to a true representation of doctors managing asthma patients in Nigeria. This study may give an insight of the unacceptable level of knowledge and use of asthma control tools in Nigeria. The limitations of this study are the convenience sampling method which may affect the external validity of the study, we are very cautious of generalizing the findings from this study to the target population and all other poor resource setting. We also noted the small sample size, low level of participation by physicians in the private hospitals and recall bias as additional limitations of the study that can affect its generalization to another setting. Taking into consideration the limitations inherent in this study, our result may implicate future study on asthma control measurement tools in health care professionals in the country.

\section{Conclusion}

The knowledge and use of asthma control measurement tools in the management of asthma among doctors in the family and internal medicine practice in Nigeria are poor. These results indicate that with the exception of pulmonologist, most doctors working as General practitioners and Internist are not giving treatment based on appropriate classification of the disease and not comply- ing with the recommended goal of asthma therapy which is to achieve clinical control. The implications of poor knowledge on asthma control measurement tools in Nigeria is that the doctors will render poor asthma care and patient will have increased morbidity and poor quality of life. Therefore there it is imperative to improve the knowledge and use of asthma control measurement tools by addressing the knowledge gap and other challenges.

\section{Source(s) of support}

Nil.

\section{Acknowledgement}

The moral support given by the Heads of Department of Medicine in the participating institutions.

\section{Conflicts of interest}

Nil.

\section{References}

1. The Global Asthma Report 2011. Paris, France: The International Union against Tuberculosis and Lung Disease, 2011. Available from: http://www.globalasthmareport.org/sites/default /files /Global_Asthma_Report_2011.pdf. Accessed September 23, 2011.

2. Mazola M, Fabian D, Holt S, Beasley R. Global Burden of Asthma. 2004. [On line]. Available: http://ginasthma. Com/ReportItem.asp? $11=2 \& 12=2 \& i n t I d=95$ [date last accessed 19 October 2012]

3. Desalu OO, Onyedum CC, Salawu FK, Iseh KR, Salami AK. Asthma in Nigeria: are the resources available to support internationally endorsed standards of care? Health Policy 2011; 99: 250-254 PubMed. doi: 10.1016/j. healthpol.2010.10.006

4. Global Initiative for Asthma. Global Strategy for Asthma Management and Prevention - 2010 updated. Geneva: Global Initiative for Asthma, 2010. Available at:http:// www. ginasthma.org/local/uploads/files/GINA_Report_2010_1.pdf. Accessed July 5, 2011.

5. Global Initiative for Asthma. Global strategy for asthma management and prevention 2006. Available fromhttp:// www.who.int/respiratory/asthma/GINA_WR_2006_ copy yright\%5B1\% 5D.pdf.Accessed: August 21, 2007.

6. Juniper EF, Svensson K, Mork A, Stahl E. Measurement properties and interpretation of three shortened versions of the asthma control questionnaire. Respir Med 2005; 99: 553 http://dx.doi.org/10.1016/j.rmed.2004.10.008 
7. Chhabra SK. Assessment of Control in Asthma: The New Focus in Management. Indian J Chest Dis Allied Sci 2008; 50: 109-116http://medind.nic.in/iae/t08/i1/iaet08i1p109.pdf

8. Teeter JG, Bleecker ER. Relationship between airway obstruction and respiratory symptoms in adult asthmatics. Chest 1998; 113: 272-7 PubMed. doi:10.1378/ chest.113.2.272

9. Juniper EF, O'Byrne PM, Roberts JN. Measuring asthma control in group studies: do we need airway calibre and rescue b2-agonist use? Respir Med 2001; 95: 319- PubMed ;323 DOI: http://dx.doi.org/10.1053/rmed.2001.1034 10. Bateman ED, Boushey HA, Bousquet J, Busse WW, Clark TJ, Pauwels RA, Pedersen SE; GOAL Investigators Group. Can guideline-defined asthma control be achieved? The gaining optimal asthma control study. Am J Respir Crit Care Med 2004; 170(8): 836-844. doi/ abs/10.1164/rccm.200401-033OC

11. Rabe KF, Vermeire PA, Soriano JB, Maier WC. Clinical management of asthma in 1999: the Asthma Insights and Reality in Europe (AIRE) study. Euro Respir J. 2000; 16(5):802 PubMed -807. http://erj.ersjournals.com/content/16/5/802.full.pdf + html

12. Partridge MR, van der Molen T, Myrseth SE, Busse WW. Attitudes and actions of asthma patients on regular maintenance therapy: the INSPIRE study. BMC 2006, 6(13). DOI: 10.1186/1471-2466-6-13

13. Rabe KF, Adachi M, Lai CK, Soriano JB, Vermeire PA, Weiss KB et al. Worldwide severity and control of asthma in children and adults: the global asthma insights and reality surveys. J Allergy Clin Immunol 2004; 114:4047. http://dx.doi.org/10.1016/j.jaci.2004.04.042

14. Desalu, OO, Fawibe AE, Salami AK. Assessment of the level of asthma control among adult patients in tertiary care centres in Nigeria. Journal of Asthma 2012.DOI: 10.3109/02770 903.2012.690478.

15. Adeyeye OO Onadeko BO, Understanding medication and use of drug delivery device by asthmatic in Lagos. West Afr J Med. 2008 ;27:155-159 PubMed. doi: 10.1186/1755-7682-5-20

16. Ozoh OB, Niideka NU, Chukwu CC ,Bandele EO, Irusen E .The ACT and the ATAQ Are Useful Surrogates for Asthma Control in Resource-Poor Countries with Inadequate Spirometric Facilities . Journal of Asthma 2012. doi:10.3109/02770903.2012.729632

17. Renzi PM, Ghezzo H, Goulet S, Dorval E, Thivierge RL. Paper stamp checklist tool enhances asthma guide- lines knowledge and implementation by primary care physicians. Can Respir J. 2006; 13:193-197. http://www. ncbi.nlm.nih.gov/pmc/articles /PMC2 683278/pdf/ crj13193.pdf

18. Haughney J, Price D, Kaplan A, Chrystyn H, Horne R, May N, Moffat M, Versnel J, Shanahan ER, Hillyer EV, Tunsäter A, Bjermer Achieving asthma control in practice: understanding the reasons for poor control. Respir Med 2008; 102(12):1681-1693. http://dx.doi.org/10.1016/j. rmed.2008.08.003

19. Stanford RH, Gilsenan AW, Ziemiecki R, Zhou X, Lincourt WR, Ortega H. Predictors of uncontrolled asthma in adult and pediatric patients: analysis of the Asthma Control Characteristics and Prevalence Survey Studies (ACCESS). J Asthma 2010; 47(3):257-262. doi: 10.3109/02770900903584019

20. Wu AW, Young Y, Skinner EA, Diette GB, Huber M, Peres A, Duality of care and outcomes of adults with asthma treated by specialists and generalists in managed care. Arch Intern Med. 2001; 161(21):2554-2560. doi:10.1001/archinte.161.21.2554

21. Boulet LP, Borduas F, Bouchard J, Blais J, Hargreave FE, Rouleau M. Playing cards on asthma management: a new interactive method for knowledge transfer to primary care physicians. Can Respir J. 2007;14(8):480-484 http:/ / www.ncbi.nlm.nih.gov/pmc/articles/ PMC2677773/ pdf/crj14480.pdf

22. Braido F, Baiardini I, Stagi E, Piroddi MG, Balestracci S, Canonica GW. Unsatisfactory Asthma Control: Astonishing Evidence from General Practitioners andRespiratory Medicine Specialists. I Investig Allergol Clin Immunol 2010;20(1): 9-12 http://www.jiaci.org/issues/vol20issue1/2.pdf

23. Ozoh OB, Bandele EO. A synopsis of asthma research in Nigeria between 1970 and 2010. African Journal of Respiratory Medicine 2012 ;7:5-11 http:/ / www.africanjournalofrespiratorymedicine.com/articles/march_2012/ AJRM\%20MARCH\%205-11.pdf

24. Cabana MD, Rand CS, Powe NR, Wu AW, Wilson $\mathrm{MH}$, Abboud PC, et al. Why don't physicians follow clinical practice guidelines? A framework for improvement. JAMA 1999; 282:1458 65. http://dx.doi.org/10.1542/ peds.2005-1055

25. Umoh VA, Ukpe IE. Knowledge of the asthma guidelines among doctors in a tertiary hospital in Nigeria. Indian J Allergy Asthma Immunol 2012; 26:77-82. DOI: 10.4103/0972-6691.112552 
26. Holt S, Sheahan D, Mackey B, Jacobsen C. Use of Asthma Control Test (ACT)affects New Zealand primary care doctors' perception of asthma control. NZMJ 2011; 124:99-101 http://www.ncbi.nlm.nih.gov/ pubmed/21946753

27. Smart A. A multi-dimensional model of clinical utility. International Journal for Quality in Health Care 2006 International Journal for Quality in Health Care 2006; 18(5): 377-382. DOI: http://dx.doi.org/10.1093/intqhc/ mzl034

28. First MB, Pincus HA, Levine JB, Williams JBW, Ustun B, Peel R. Clinical utility as a criterion for revising psychiatric diagnoses. Am J Psychiatry 2004; 161: 946-954 http://dx.doi.org/10.1176/appi.ajp.161.6.946

29. Davis D, O'Brien MA, Freemantle N, Wolf FM,
Mazmanian P, Taylor-Vaisey A. Impact of formal continuing medical education: Do conferences, workshops, rounds, and other traditional continuing education activities change physician behavior or health care outcomes? JAMA. 1999; 282:867-874.http://dx.doi.org/10.1176/ appi.ajp.161.6.946

30. Thomson O'Brien MA, Freemantle N, Oxman AD, Wolf F, Davis DA, Herrin J. Continuing education meetings and workshops: Effects on professional practice and health care outcomes. Cochrane Database Syst Rev. 2001 ; 2):CD003030. DOI: 10.1002/14651858.CD003030

31. Cabana MD, Slish KK, Evans D, Mellins RB, Brown RW, Lin X, Kaciroti N, et al. Impact of physician asthma care education on patient outcomes. Pediatrics. 2006; 117(6):2149 PubMed -2157. http://dx.doi.org/10.1542/ peds.2005-1055 